\title{
EXPERIMENTAL PRESSURES EXERTED BY MAIZE IN SLENDER CYLINDRICAL SILO: COMPARISON WITH ISO 11697
}

\author{
Rômulo M. Gandia ${ }^{1 *}$, Estácio A. de Oliveira Júnior ${ }^{1}$, Francisco C. Gomes ${ }^{1}$, \\ Wisner C. de Paula ${ }^{1}$, Karoline C. Dornelas ${ }^{2}$ \\ ${ }^{1 *}$ Corresponding author. Federal University of Lavras/ Lavras - MG, Brazil. \\ E-mail: romagandia@gmail.com | ORCID: https://orcid.org/0000-0002-7786-1525
}

\begin{abstract}
KEYWORDS
funnel flow, normal pressures, frictional pressures, test silo.
\end{abstract}

\begin{abstract}
Pilot-scale test stations make it possible to obtain reliable and comparable results applicable to full-scale systems by conforming to specified proportional limits. Therefore, in this study, normal and frictional pressures were evaluated in a pilot-scale test station composed of a slender cylinder silo using maize, a free-flowing product, as the stored product. Temporal effects were analyzed and verified during filling, static, and discharge conditions. The maximum normal and frictional pressures were also evaluated. The results were compared with ISO 11697: 1995. During filling, accommodation peaks occurred only in the $\alpha: 30^{\circ}$ hopper. In general, normal pressures were higher for the flat bottom whereas higher frictional pressures occurred for the $30^{\circ}$ hopper. The maximum experimental pressures (normal and frictional) were lower than those provided by ISO 11697. Therefore, it is concluded that the coefficients used in the ISO standard are sufficient to promote safety in silo projects.
\end{abstract}

\section{INTRODUCTION}

Brazil's economic growth has been influenced by agribusiness, spurred by increasing productivity in the sector in recent years. From January to October 2020, the contribution of agribusiness to the gross internal product or produto interno bruto (PIB) was $16.81 \%$, equivalent to 274 billion reais, or approximately 49 billion USD (CEPEA, 2021). For the year 2021, agriculture production is estimated to reach 256.8 million tons, where maize represents 100.6 million tons in the first and second harvests (IBGE, 2020). Brazil, being a continental country with a favorable climate for production throughout the year, increases its agricultural export sector annually. With such production, the use of silos for the storage of products is essential, and an estimated static capacity of 171.542 billion tons is currently available (CONAB, 2020).

However, despite these significant numbers, Brazil does not have its own standard for silo design. Currently, the Brazilian standard is being discussed (CE-203:020.001 - Comissão de Estudo de Máquinas e Equipamentos para Sistemas de Armazenagem e Beneficiamento de Grãos Vegetais). The importance of a specific standard is necessary not only for structure design, but to maintain records of the properties of the products stored in the country and the properties of the building materials of the silo, in addition to cultural factors of operation regarding storage and climatic conditions.

The study of the behavior of products stored in silos was first proposed and conducted by Janssen (Janssen, 1895). Since then, various theories have been developed (Jenike \& Johanson 1973a, 1973b; Walker, 1967; Walters 1973a, 1973b) that support current international standards (ANSI, 2019; CEN, 2006; DIN, 2005; ISO, 2012).

Most standards classify a product's discharge flow graphically. ISO 11697 uses pressure graphs based on the hopper angle and on the friction angle between the grain and the silo wall. The flow can be classified into mass flow, funnel flow, or intermediate flow (mixed). Mass flow is the most desirable and, whenever feasible, a silo is designed to achieve mass flow. The advantage of mass flow is that it promotes a uniform discharge, where all particles are in motion, thus preventing the formation of static zones. In funnel flow, a channel is formed above the discharge gate, generating static side zones where the product remains

\footnotetext{
${ }^{1}$ Federal University of Lavras/ Lavras - MG, Brazil.

${ }^{2}$ Federal University of Mato Grosso/ Campus Sinop/ Sinop - MT, Brazil.
}

Area Editor: Edilson Costa

Received in: 3-11-2021

Accepted in: 9-17-2021 
stationary (Calil \& Cheung 2007; Jenike et al., 1973b, 1973a; Wójcik et al., 2012).

Flow determination is fundamental in the analysis of the forces acting on the silo, which are evaluated during the filling and discharge phases. ISO 11697 provides equations for horizontal, vertical, and frictional pressure during the filling phase in the silo cylinder and hopper. In the case of discharge, effects are described through an overpressure coefficient "C," which is established according to the slenderness (diameter) of the silo.

From several studies on silo failures and collapses (Bywalski \& Kamiński, 2019; Gutiérrez et al., 2015; Dogangun et al., 2009; Teng, 1994; Teng \& Rotter, 1989, 1991), it was found that the main causes were attributable to design error, pressure (normal and frictional, on the wall and in the hopper) created by the product stored in the structure, excess moisture in the stored product (causing unexpected overpressure), product discharge (producing maximum pressures in the silo, usually in the silo-hopper transition area), discharge eccentricity, temperature variation in the product attributed to the location of the silo, and imperfections in the structural material.

A full-scale experimental model of a silo can be used to obtain or approximate real values, making it possible to understand the effects of pressure in silos. Worldwide, the number of full-scale experimental silo stations is relatively small (Sun et al., 2020; Couto et al., 2012; Härtl et al., 2008; Ramírez et al., 2010a) because of the costs associated with construction, instrumentation, and operations. In addition, the scale factor of the plant with respect to an actual silo is extremely important for reliable data (Brown \& Nielsen 1998). Furthermore, the study of experimental pressures in silos allows advances in numerical studies as a means of validation and comparison to ensure the reliability of the models.

The pilot-scale test station proposed by Pieper and Schütz in 1980 (Pieper \& Schütz, 1980), which helped to develop DIN 1055-6: Basis of design and actions on structures-Part 6 (DIN, 2005), allows the evaluation of numerous variables that directly influence the behavior of the pressures in a silo related to any stored product, provided that the maximum diameter of the product is less than 1.7 $\mathrm{cm}$ (to be accurately proportional to the real scale) (Brown \& Nielsen, 1998; Pieper \& Schütz, 1980). The station can be used to analyze three walls having different roughness (thus varying the friction coefficient between the product and the wall), twelve height/diameter ratios, eight bottoms (one flat bottom, four concentric hoppers $\left(\alpha: 75^{\circ}\right.$ to $30^{\circ}$ ) and three $100 \%$ eccentric hoppers $\left(\alpha: 75^{\circ}\right.$ to $\left.45^{\circ}\right)$ ) and other possible procedural variables pertaining to silo storage.

Through catalogs of the main silo manufacturers in Brazil (GSI, PAGÉ, and Kepler Weber), the models of silos sold for the storage of maize and soybeans have flat bottoms or hoppers with beta of $45^{\circ}$ and $60^{\circ}$ and maximum $\mathrm{H} / \mathrm{D}$ ratio $=3$. Flat-bottom silos are widely used because they optimize storage volume, are easier to handle, and are less expensive (Calil \& Cheung, 2007). When using a flat bottom, it is necessary to use manual labor or mechanical systems to remove the remaining product at the bottom of the silo after discharge, a requirement that may not be necessary when using an inclination in the discharge base (a hopper).

Owing to the economic importance of maize, the uncertainties (Dogangun et al., 2009) in silo pressures and the high number of slender silos and funnel flow silos used in Brazil, this study aims to provide information to support a Brazilian standard. In addition, the objective of this study was to experimentally evaluate the pressures using maize, a free-flow product, in a slender silo considering hopper and flat bottom configurations, and to compare the values obtained to those of ISO 11697.

\section{MATERIAL AND METHODS}

\section{General description of the installation}

Tests were conducted at the test station located in the Federal University of Lavras (UFLA) in the Laboratorio de propriedades físicas e de fluxo de produtos armazenados. The station was previously validated by our research team regarding pressure and flow in silos associated with stored products (Gandia et al., 2021). The station (Figure 1) consists of a storage silo where the product to be tested is stored, a bucket elevator that transports the material, and an instrumented pilot silo for pressure analysis. 


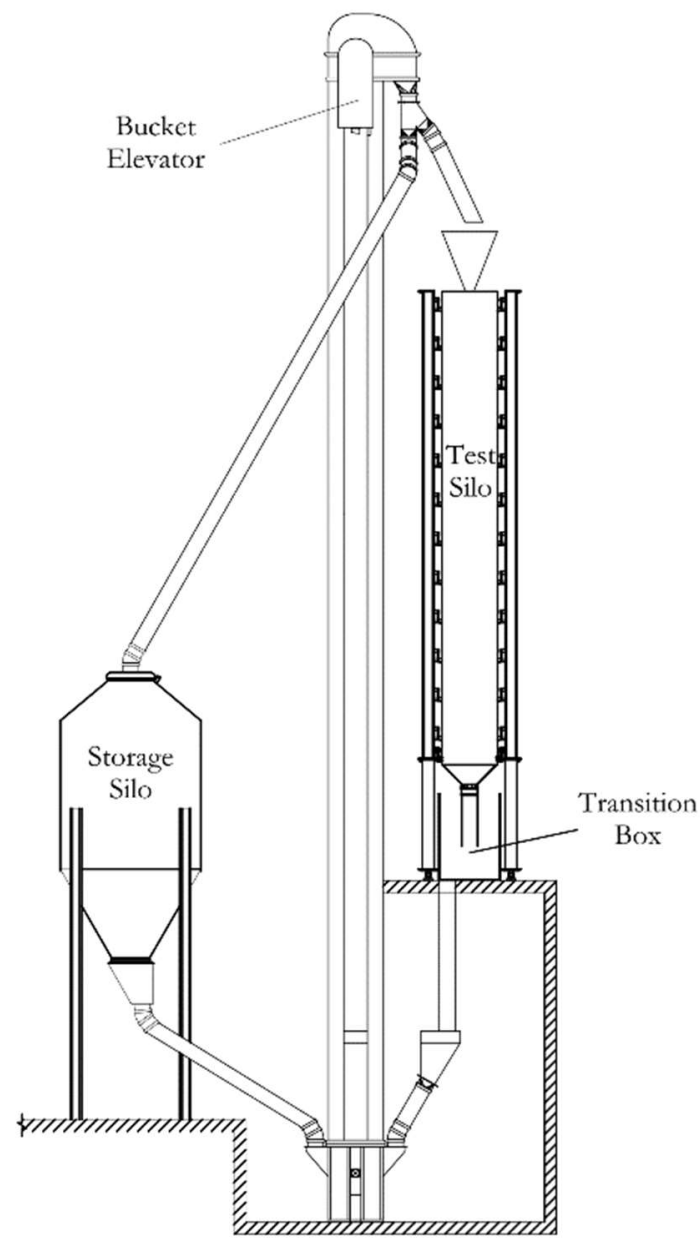

FIGURE 1. Pilot silo test station.

\section{Geometry of pilot silo}

The pilot silo has a total height of $6 \mathrm{~m}$ and is subdivided into 12 independent and suspended rings (495 mm height and $688 \mathrm{~mm}$ internal diameter each). The silo wall consists of smooth galvanized steel with a thickness of $10 \mathrm{~mm}$, designed to ensure that the stresses created during the tests are transferred to the wall without deformation of the same.

Each ring has a vertical cut with a spacing of $5 \mathrm{~mm}$ in the gap between rings, which guarantees structural interdependence. The instrumentation of each ring consists of two pairs of traction load cells. The first pair is located in the center and is perpendicular to the vertical opening of the ring, determining the horizontal pressure on the wall, which in its normal state is pre-tensioned with three helical springs, making the setup more sensitive to any stress effects (Figure 2). The second pair is located next to the outer wall of the ring and is fixed using clamps articulated to the pillars of the silo and measures any vertical acting force (Figure 2).
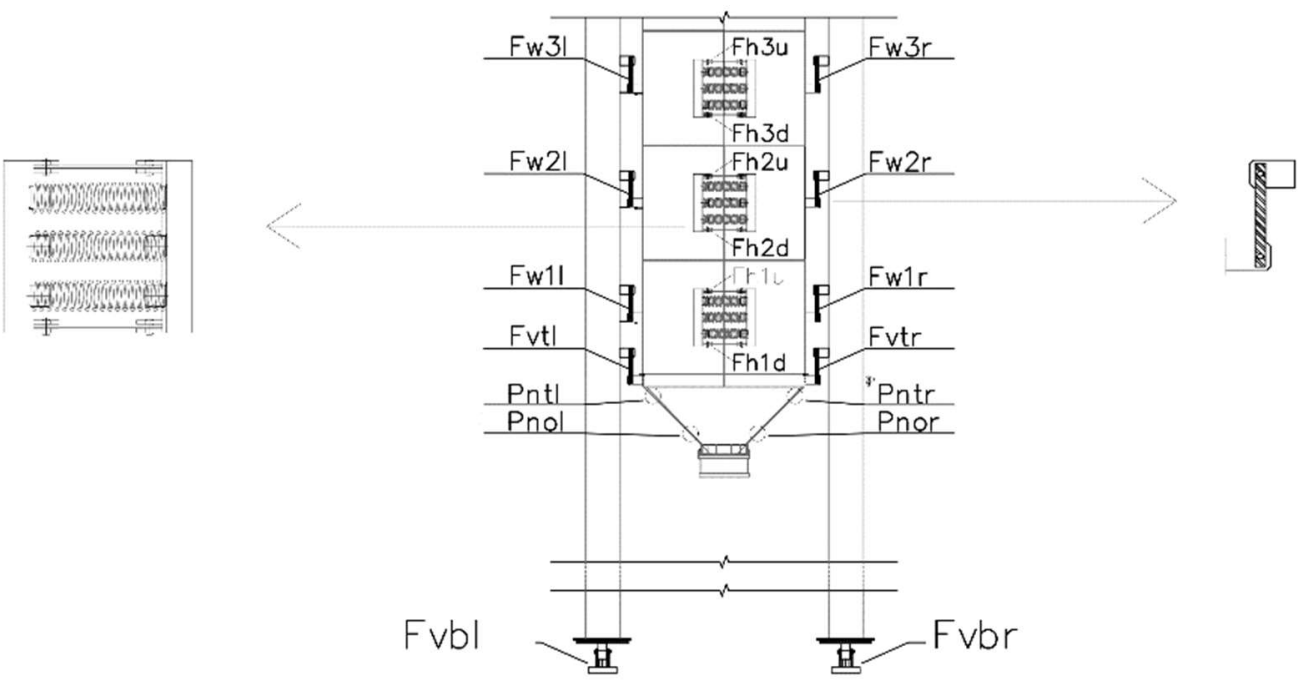

FIGURE 2. Locations of measurement cells. 
The rings are suspended and supported by three pillars, one of which only has the function of stabilizing the rings and preventing rotation. The other two have a beam

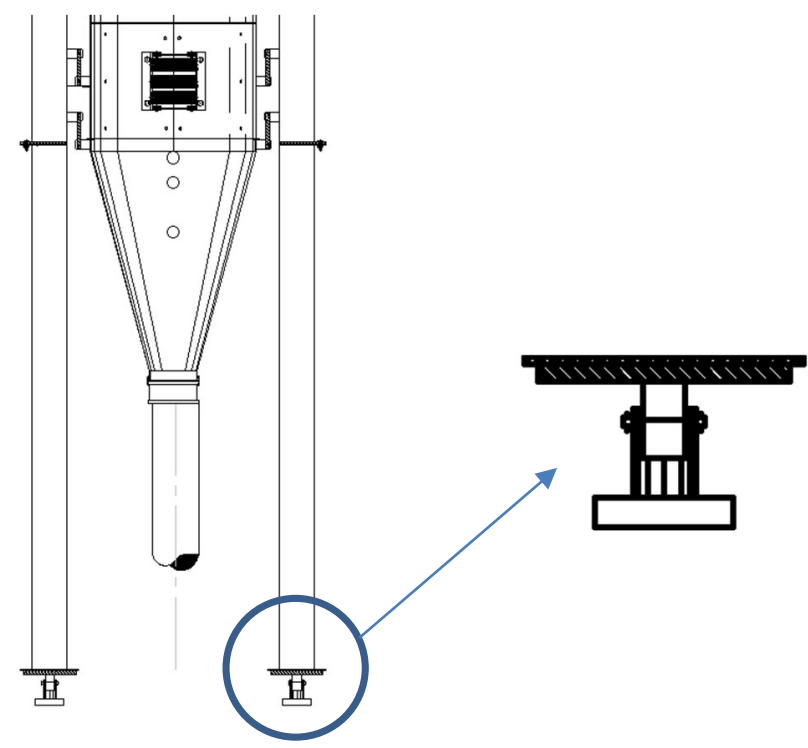

load cell with a capacity of $50 \mathrm{kN}$ at their base, which allow the weight of the stored product to be determined from the sum of the load on the two pillars (Figure 3).

FIGURE 3. Support pillars and locations of beam load cells.

The station allows four hopper configurations with a concentric discharge $\left(\alpha: 30^{\circ}, 45^{\circ}, 60^{\circ}\right.$, and $\left.75^{\circ}\right)$, three eccentric hoppers $\left(\alpha: 45^{\circ}, 60^{\circ}\right.$, and $\left.75^{\circ}\right)$, and a flat bottom with concentric discharge. The $\alpha: 30^{\circ}$ hopper and the flat
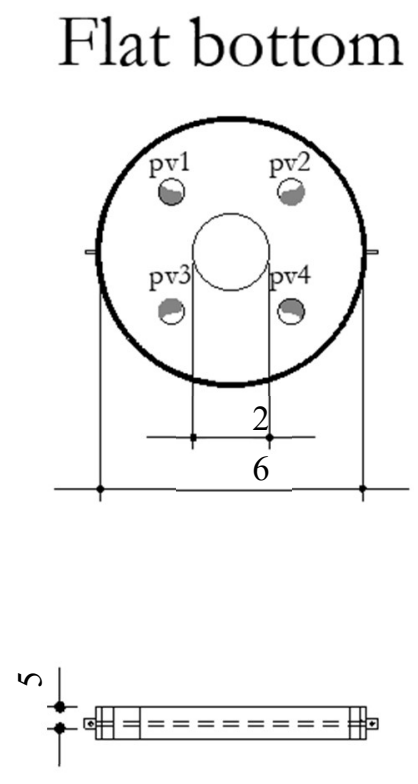

bottom used in this study were instrumented using four pressure cells distributed and attached to their walls, as shown in Figure 4.

\section{Concentric}

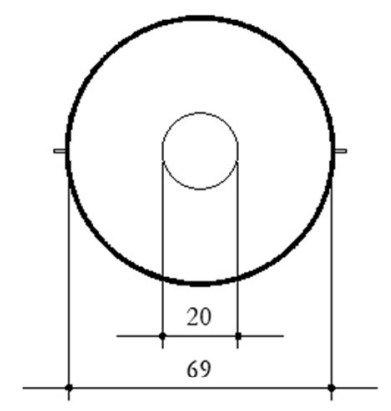

$$
\alpha=30^{\circ}
$$

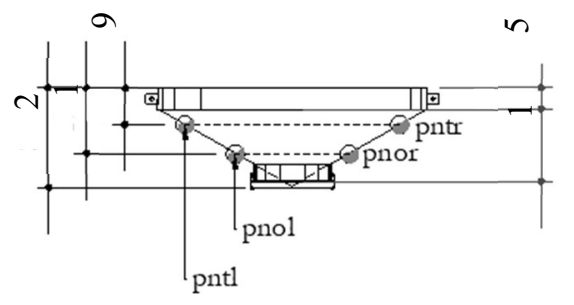

FIGURE 4. Hopper geometry and positioning of pressure cells.

During the experiments, the hopper was connected to the support pillars. Each support pillar has a set of one clamp and one traction load cell, which have articulated connections at both ends and are connected through a stainless-steel pin. The same system was used in the vertical support of each ring (Figure 2).
The acquisition of electrical signals (in $\mathrm{mV} / \mathrm{V}$ ) was performed by a module (LYNX model DS2000) with a capacity of 64 channels and a maximum frequency of 65.5 $\mathrm{kHz}$. The calibration and treatment of the data were performed using the Aqdados software package (version 7.5). 


\section{Description of tests}

The physical characteristics of the maize were determined at the Centro de Tecnologia e Recursos Naturais da Universidade Federal de Campina Grande (UFCG), using Jenike's shear device (Jenike Shear Cell) (Building, 1989).

Pressure analysis was performed during filling, static, and discharge phases. The filling height of the product was $1.50 \mathrm{~m}$, and the height/diameter ratio was 2.18 . The acquisition system was configured to collect data at a frequency of $2 \mathrm{~Hz}$. The test variables were as follows: $\alpha: 30^{\circ}$ hopper and flat bottom, both with concentric discharge. Three repetitions were performed to evaluate each variable, totaling six complete tests.
The maize was transferred to the pilot silo through a bucket elevator that provided constant flow and centralized filling until the grain mass reached a height of approximately $1.5 \mathrm{~m}$. After filling, the maize was allowed to settle for $10 \mathrm{~min}$ (static condition) to stabilize the system and accommodate the stored product.

Figure 5 shows the three phases (filling, static, and discharge) At the discharge, the hopper gate was completely open, promoting free discharge, where the highest pressure was expected in this stage. After opening the discharge gate, the maize fell into the transition box so as not to exceed the bucket elevator carrying capacity. Finally, the product was transferred from the transition box to the storage silo using the bucket elevator, completing the test.

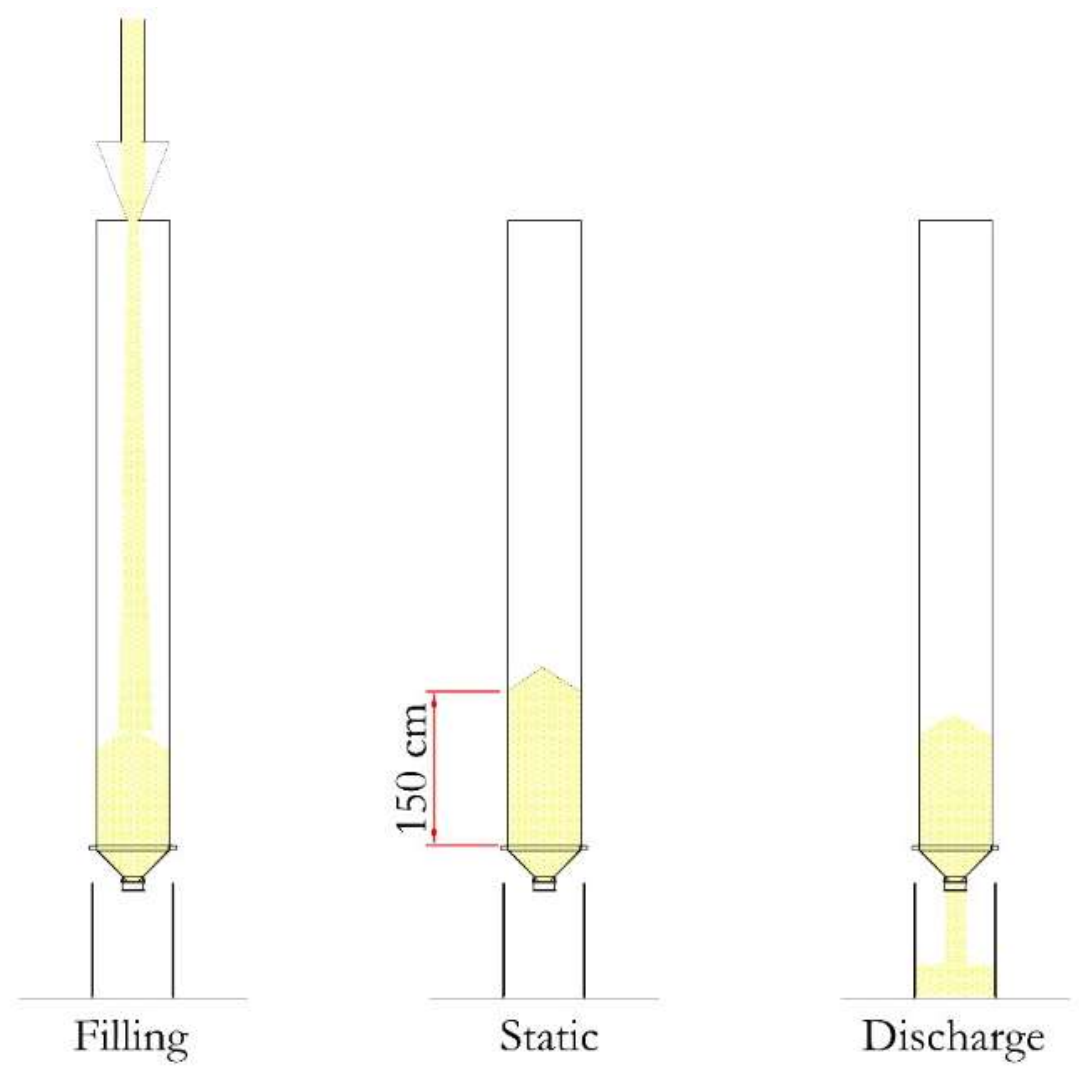

FIGURE 5. Testing stage: Filling, static, and discharge conditions.

According to ISO 11697 (ISO, 2012), flow characterization (available from ISO "Figure 2 - Limit between mass flow and funnel flow for circular hoppers"), the friction coefficient for maize is $7.38-9.23$ and funnel flow discharge characteristics for the $30^{\circ}$ hopper and flat bottom were evaluated based on this friction coefficient.

\section{RESULTS AND DISCUSSION}

To evaluate the uniformity of the repetitions of the tests and the difference between the two configurations, Table 1 presents the average loading values (weight of the stored product) during the filling and discharge phases in the pilot silo.

TABLE 1. Product weight.

\begin{tabular}{ccccccc}
\hline & \multicolumn{2}{c}{ Average value $(\mathrm{kN})$} & & \multicolumn{2}{c}{ Standard deviation $(\%)$} \\
\cline { 2 - 3 } \cline { 5 - 6 } Concentric $\left(\alpha=30^{\circ}\right)$ & Filling & Discharge & & Filling & \multicolumn{2}{c}{ Discharge } \\
\cline { 2 - 3 } Flat Bottom & 5.4 & 5.5 & & 7.3 & 7.4 & 3.9 \\
\hline
\end{tabular}

From this information, it is possible to verify that the repetitions between each configuration presented low variability (statistically equal). It is also possible to state that the two configurations differ because of the greater volume of the $30^{\circ}$ hopper. 
Table 2 shows the average of the times in each phase of the tests and the standard deviation calculated for the test repetitions.

TABLE 2. Trial time.

\begin{tabular}{|c|c|c|c|c|c|c|}
\hline \multirow[b]{2}{*}{ Test } & \multicolumn{3}{|c|}{ Average value (s) } & \multicolumn{3}{|c|}{ Standard deviation $(\%)$} \\
\hline & Filling & Static & Discharge & Filling & Static & Discharge \\
\hline Concentric $\left(\alpha=30^{\circ}\right)$ & 189.0 & 646.2 & 47.2 & 8.9 & 2.3 & 27.5 \\
\hline Flat Bottom & 189.3 & 631.5 & 34.8 & 3.0 & 1.6 & 30.4 \\
\hline
\end{tabular}

There was considerable deviation in the discharge phase, which was caused by turbulence and complexity in the flow. To verify that the same test conditions were present, the discharge flow between the two configurations was compared (Table 3 ).

TABLE 3. Average flow rate for each test.

\begin{tabular}{cccccc}
\hline & \multicolumn{2}{c}{ Average value $(\mathrm{Kg} / \mathrm{s})$} & & \multicolumn{2}{c}{ Standard deviation $(\%)$} \\
\cline { 2 - 3 } \cline { 5 - 6 } Test & Filling & Discharge & & Filling & Discharge \\
\hline Concentric $\left(\alpha=30^{\circ}\right)$ & 2.9 & 12.8 & & 1.9 & 38.3 \\
Flat Bottom & 2.8 & 15.7 & & 5.6 & 36.6 \\
\hline
\end{tabular}

The filling flow rate, in addition to having a relatively low deviation between repetitions, was statistically equal between the two configurations. As expected, the discharge rate deviation was higher. The deviation between repetitions is relatively greater than for filling because of the funnel flow pattern (ISO, 2012), exhibiting random behavior during the discharge phase
(Calil \& Cheung, 2007; Jenike et al., 1973b).

This study generated a large volume of data. Therefore, to avoid presenting unnecessary data, Tables 4 and 5 present the average values from each measurement cell obtained from the pilot silo instrumentation for the $30^{\circ}$ concentric hopper and flat bottom configurations, respectively, in the three phases.

TABLE 4. Mean pressure values in the hopper configuration $\left(\alpha=30^{\circ}\right)$.

\begin{tabular}{|c|c|c|c|c|c|c|}
\hline \multirow[b]{2}{*}{ Sensor } & \multicolumn{3}{|c|}{ Load $(\mathrm{kPa})$} & \multicolumn{3}{|c|}{ Standard deviation (\%) } \\
\hline & Filling & Static & Discharge & Filling & Static & Discharge \\
\hline ph3 & 0.78 & 0.91 & 1.55 & 19.97 & 15.25 & 11.12 \\
\hline $\mathrm{ph} 2$ & 1.70 & 1.92 & 2.81 & 15.41 & 11.50 & 6.82 \\
\hline ph1 & 2.95 & 3.32 & 3.43 & 3.32 & 9.49 & 3.19 \\
\hline pntr & 1.17 & 1.27 & 11.16 & 17.15 & 25.80 & 15.56 \\
\hline pntl & 1.71 & 1.21 & 10.88 & 19.11 & 29.72 & 14.82 \\
\hline pnor & 5.87 & 6.42 & 5.23 & 12.49 & 9.21 & 10.83 \\
\hline pnol & 4.55 & 4.96 & 4.88 & 15.09 & 17.92 & 16.70 \\
\hline pvt & 10.20 & 10.67 & 10.07 & 3.85 & 3.00 & 2.29 \\
\hline pw3 & 0.21 & 0.30 & 0.40 & 7.35 & 4.76 & 9.40 \\
\hline pw2 & 0.47 & 0.55 & 0.65 & 18.01 & 7.85 & 3.99 \\
\hline pw1 & 1.06 & 1.08 & 1.13 & 13.34 & 11.44 & 10.55 \\
\hline
\end{tabular}

TABLE 5. Mean pressure values in the flat bottom configuration.

\begin{tabular}{|c|c|c|c|c|c|c|}
\hline \multirow[b]{2}{*}{ Sensor } & \multicolumn{3}{|c|}{ Load $(\mathrm{kPa})$} & \multicolumn{3}{|c|}{ Standard deviation (\%) } \\
\hline & Filling & Static & Discharge & Filling & Static & Discharge \\
\hline ph3 & 0.91 & 0.90 & 1.55 & 44.37 & 45.80 & 39.04 \\
\hline $\mathrm{ph} 2$ & 2.50 & 2.51 & 2.81 & 6.89 & 6.65 & 6.51 \\
\hline ph1 & 3.82 & 3.82 & 4.34 & 4.67 & 4.86 & 2.87 \\
\hline pv1 & 7.84 & 7.93 & 8.11 & 10.72 & 10.07 & 7.54 \\
\hline pv2 & 7.30 & 7.44 & 8.43 & 6.90 & 6.08 & 3.19 \\
\hline pv3 & 8.93 & 9.04 & 9.41 & 9.51 & 9.28 & 8.40 \\
\hline pv4 & 5.68 & 5.79 & 6.71 & 1.72 & 2.50 & 8.04 \\
\hline pvt & 10.34 & 10.33 & 9.59 & 2.74 & 2.81 & 4.88 \\
\hline pw3 & 0.18 & 0.22 & 0.36 & 11.93 & 11.51 & 22.22 \\
\hline pw2 & 0.45 & 0.50 & 0.61 & 2.17 & 1.53 & 12.78 \\
\hline pw1 & 0.95 & 0.95 & 0.86 & 3.37 & 3.18 & 9.30 \\
\hline
\end{tabular}


One of the three repetitions of each configuration is shown (chosen randomly). The results show the pressures in three regions of the silo: cylinder (normal pressure and friction), transition (tension caused by the product being stored during the transition phase), and flat or $30^{\circ}$ hopper bottom (normal pressure). The analysis of the results is discussed based on three phases: filling, static, and discharge.

\section{Concentric $\left(\alpha=30^{\circ}\right)$}

The temporal analysis of the behavior of the normal pressures in the silo with a $30^{\circ}$ hopper during the three phases is shown in Figure 6.

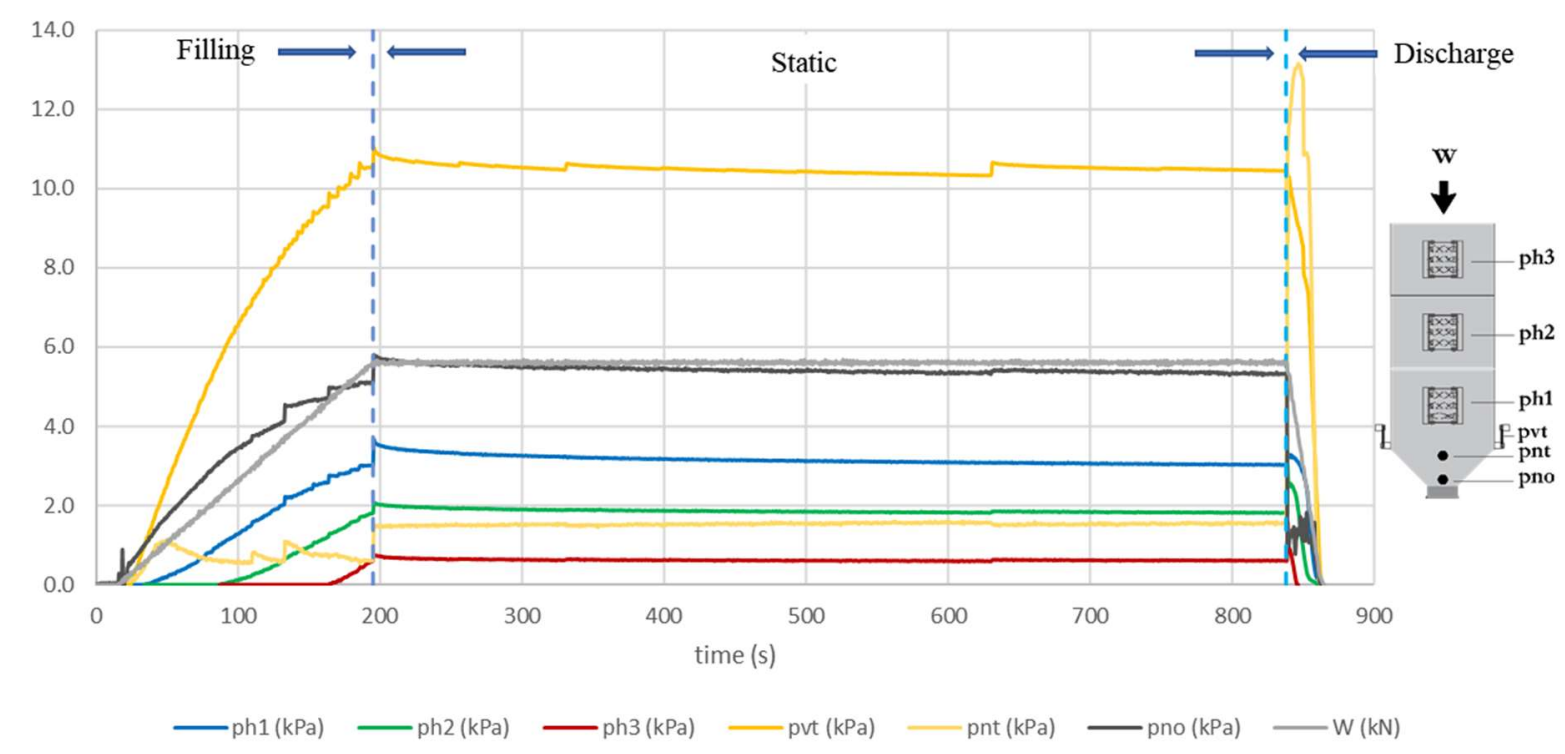

FIGURE 6. Normal pressures on the silo wall (ph, i; pnt; pno), vertical stress in the stored material at the transition (pvt) and the weight of the stored material (W) using $30^{\circ}$ hopper.

There is an increase in pressure near the hopper outlet (pno) in the first seconds of filling, which is explained by the height as the product falls to the bottom of the silo ( 6 $\mathrm{m})$. The weight of the stored product (W) does not vary, so it exhibits a linear behavior with respect to pressure throughout the test, allowing us to obtain the flow rate during the filling and discharge steps (Table 3).
The maximum pressure occurred in the silo-hopper transition (pnt) shortly after the beginning of the discharge of the product (ISO, 2012), and is a well-known behavior (Härtl et al. 2008; Ramírez et al., 2010b). Additionally, frictional pressures were obtained in the cylinder, as shown in Figure 8.

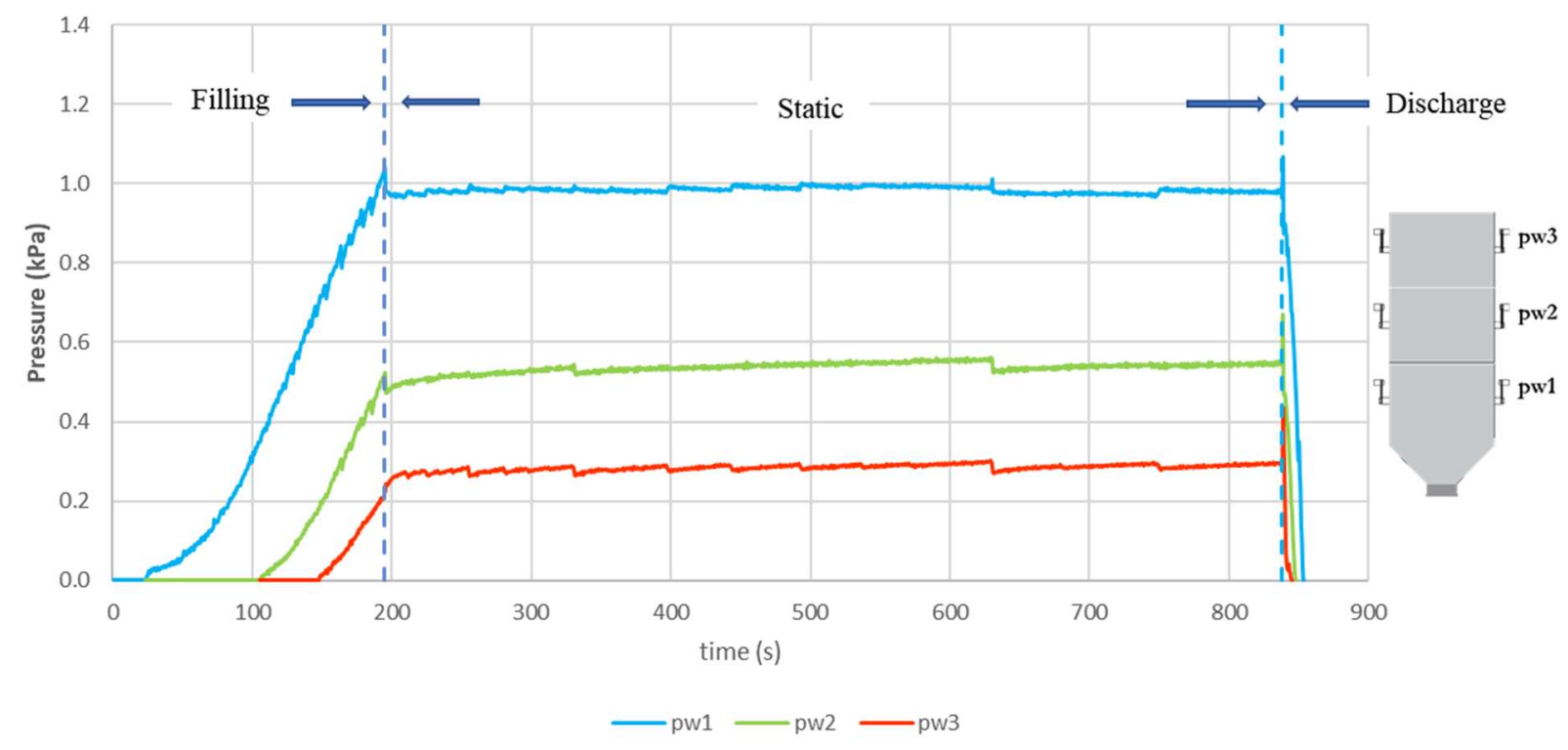

FIGURE 7. Friction pressures on the silo wall (pw, i) using $30^{\circ}$ hopper. 
Figure 7 verifies the quality of the instrumentation. During filling, the beginning of the measurements in each of the rings is observed, with temporal intervals that confirm the precision of the instrumentation. In addition, during the static phase, the peaks related to the accommodation (settling) of the material can be observed, which are synchronous in all measurement cells, regardless of whether they are pressure or load cells.

Another observation related to the static phase is related to the vertical stress caused by the stored material at the transition (pvt) and to the friction pressure in the cylinder (pwi). It is observed that while frictional pressures show decreasing accommodation peaks, the vertical stress in the stored material at the transition (pvt) shows increasing accommodation peaks. In other words, while the stored product accommodates and tends to move slightly vertically, decreasing the frictional force in the cylinder, a simultaneous increase in vertical stress in the stored material at the transition (pvt) occurs owing to the increase in the vertical pressure caused by the movement of the stored product.

\section{Flat bottom}

The temporal analysis behavior of normal pressures in the flat bottom silo during the three phases is shown in Figure 8 .

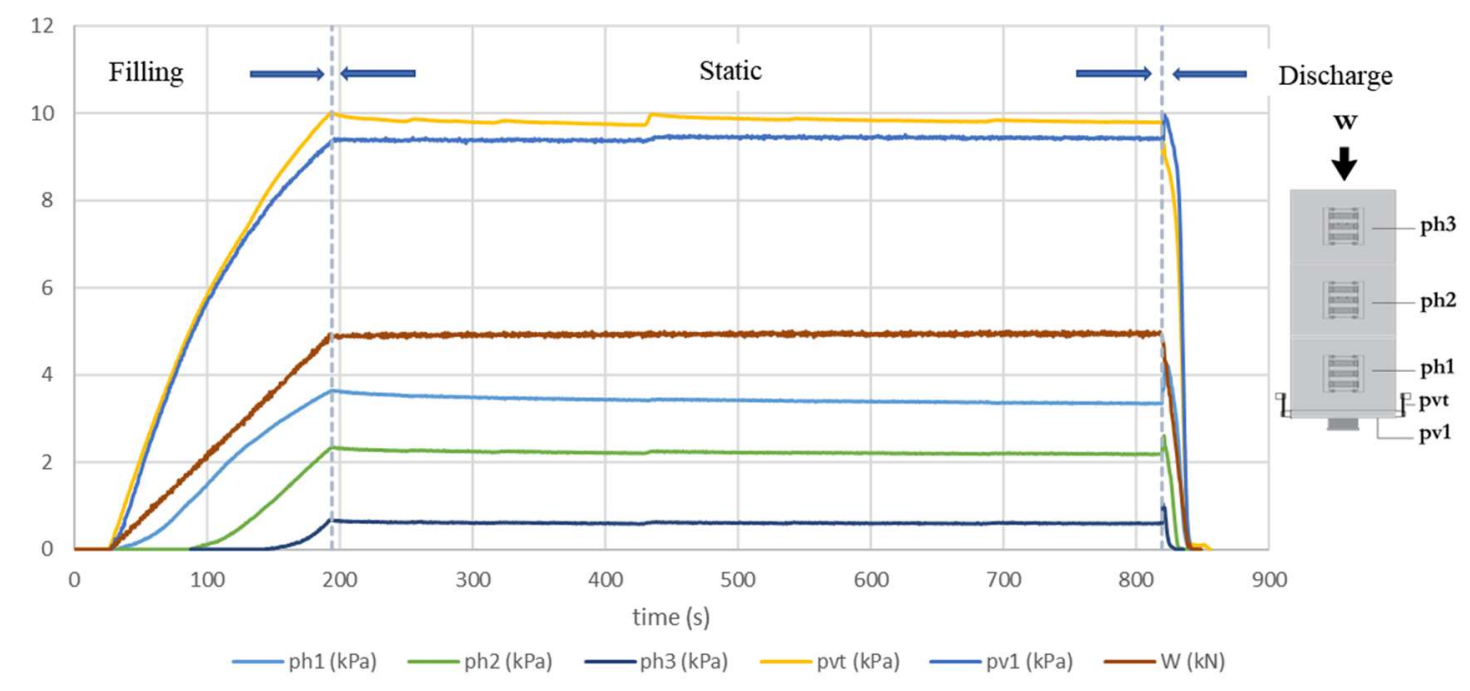

FIGURE 8. Normal pressures on the silo wall (ph, i; pnt; pno), vertical stress in the stored material at the transition (pvt) and the weight of the stored material (W) using flat bottom.

The filling phase for a flat bottom differs from the $30^{\circ}$ hopper, as no accommodation peaks are observed during filling. The reason is that with the $30^{\circ}$ hopper, the material is destabilized at the bottom of the silo because of the inclination of the hopper, promoting the accommodation of the material during filling, unlike the flat bottom, in which the material stabilizes during filling, and there is no such accommodation.

As predicted, the normal pressure at the bottom (pv1) is very similar to the vertical stress in the stored material at the transition (pvt). In general, the normal pressures in the cylinder in the filling and static phases are higher for a low-inclination hopper (in this case a flat bottom). Therefore, it is observed that for the flat bottom, the pressures are greater than those of the $\alpha=30^{\circ}$ hopper; however, in the discharge, the opposite occurs, and greater pressure peaks are observed for greater inclinations (CEN, 2006; ISO, 2012; Jenike, 1964; Jenike et al., 1973a; Wójcik et al., 2012). The frictional pressures for the flat bottom silo are shown in Figure 9.

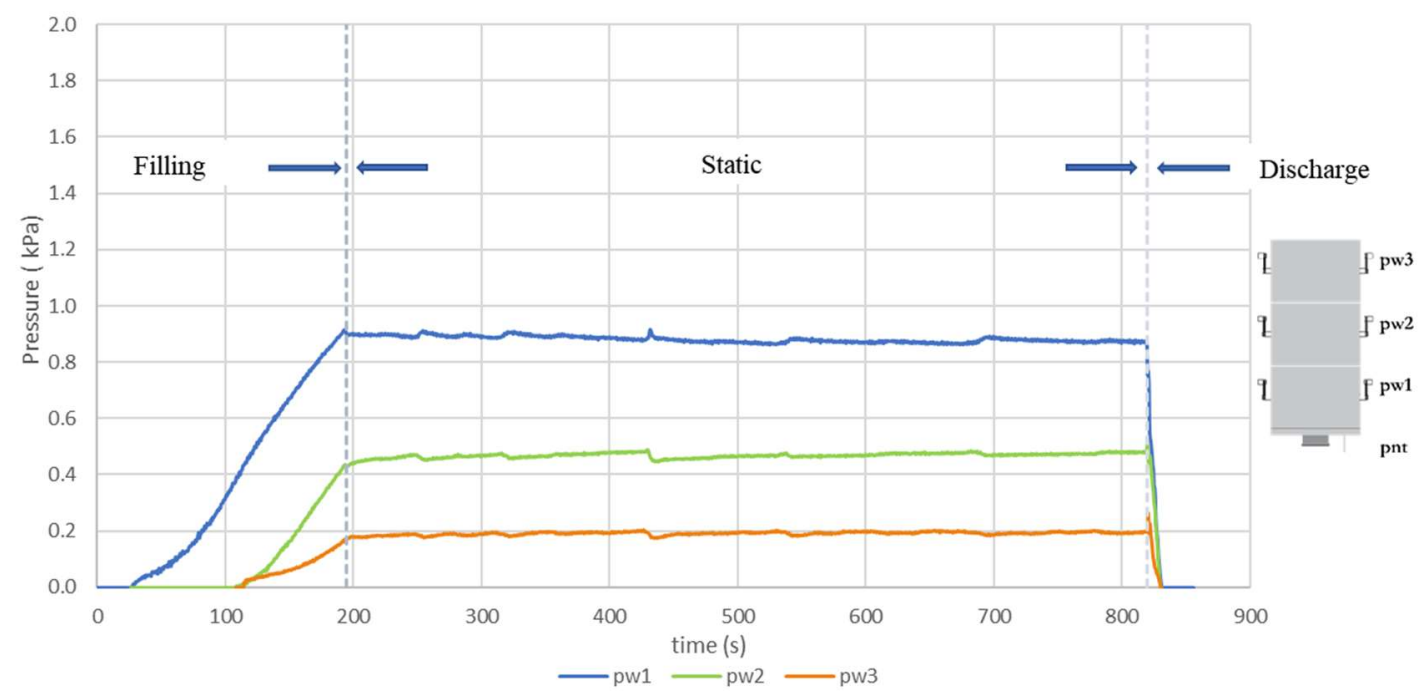

FIGURE 9. Friction pressures on the silo wall (pw, i) using flat bottom. 
Once again, it was possible to observe the quality of the instrumentation based on the time intervals during filling in the rings and also by the synchrony among the accommodation peaks during the static phase. The friction pressure in ring 3 (pw3) was observed to begin at the same time as ring 2 (pw2). A possible reason for this unexpected result is the dissipation of the product in the discharge resulting from the slenderness of the pilot silo, promoting the beginning of a vertical force at the height of ring 3 before the grain mass actually reaches this level.
As previously mentioned, the friction pressure (pwi) and the vertical stress in the stored material at the transition (pvt) exhibit the same behavior during the static phase as occurred for the $30^{\circ}$ hopper.

\section{Filling}

During filling, the pressures exhibited different time patterns. In Figures 10 and 11, the normal pressures up to a height of $1.50 \mathrm{~m}$ and the vertical stress in the stored material at the transition (pvt) are shown for the $30^{\circ}$ hopper and the flat bottom, respectively.

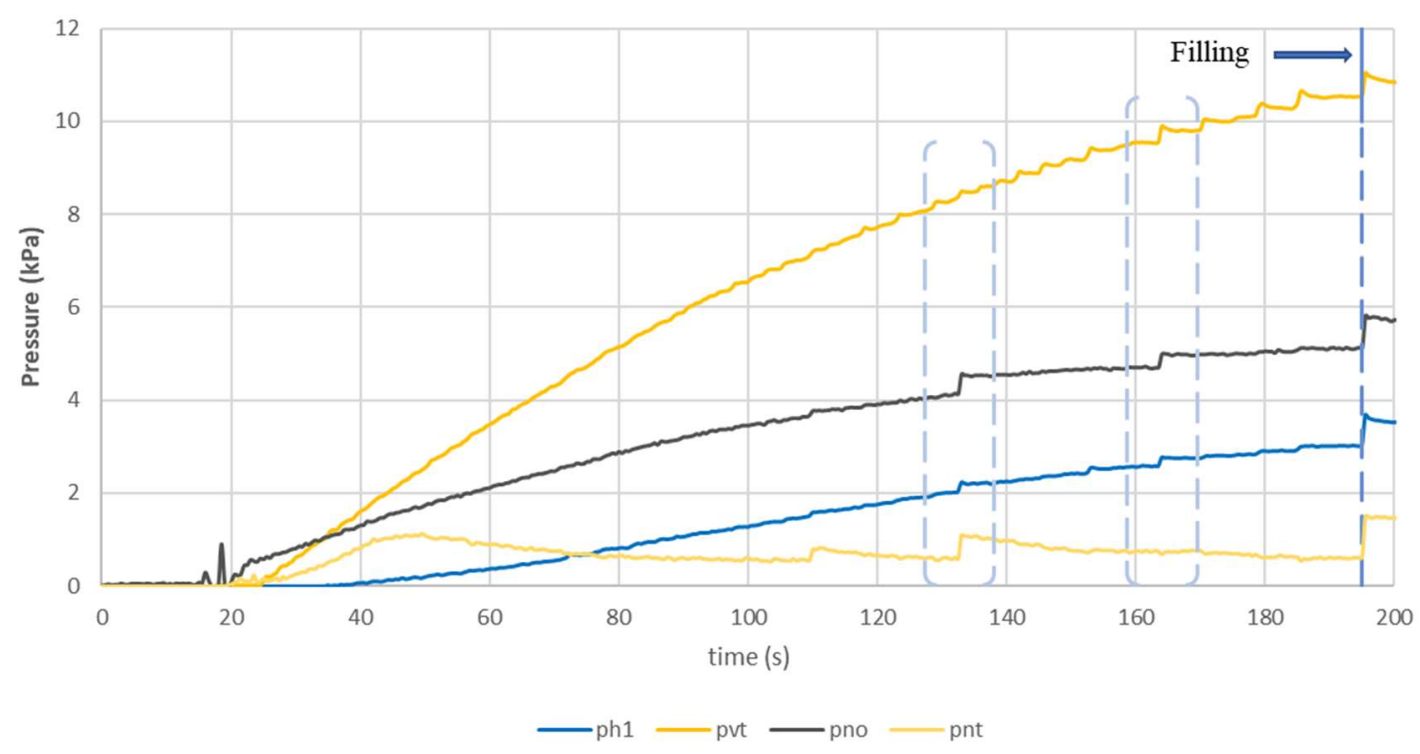

FIGURE 10. Filling pressures, $30^{\circ}$ hopper.

The fluctuations in the accommodation of the material during filling due to the inclination of the hopper can be observed in Figure 10. The greater the height of the product in the silo (the greater the weight of the grain mass), the greater the magnitude of the accommodation peaks at 126.5 and $171 \mathrm{~s}$ and also when filling is completed. The behavior of pressures on the flat bottom exhibits some differences (Figure 11).

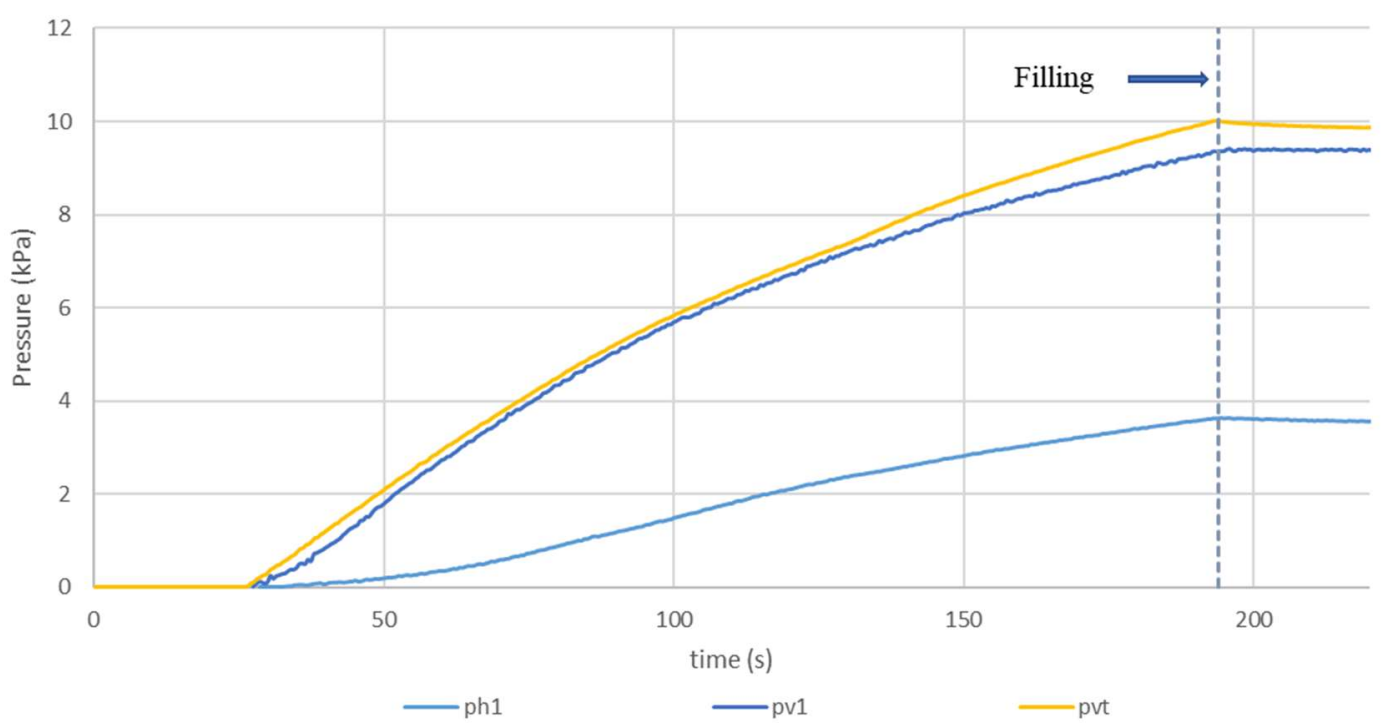

FIGURE 11. Filling pressures, flat bottom. 
As explained above, because of the stabilization provided by the flat bottom $\left(90^{\circ}\right.$ angle), the pressures do not fluctuate significantly.

\section{Static}

Observations regarding the nonlinearities of the material pressures during the static condition, that is, after accommodation, were discussed for the first time in 2012 (Couto et al., 2013b; Ruiz et al., 2012). Figures 12 and 13 show an enhanced visualization of the static condition regarding the normal and frictional pressures in the silo for the $\alpha=30^{\circ}$ hopper and the flat bottom, respectively.

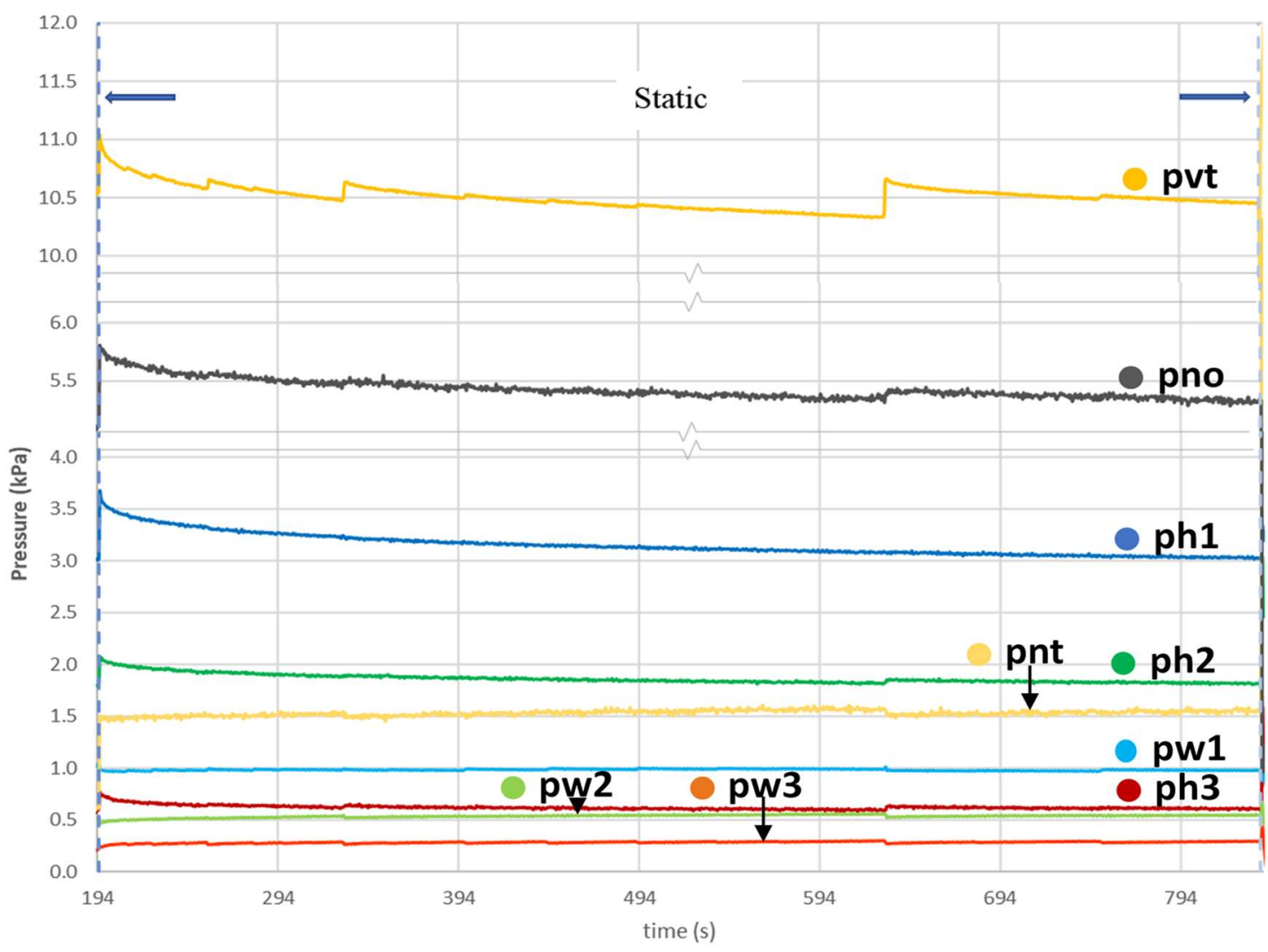

FIGURE 12. Pressures in static condition, $30^{\circ}$ hopper.

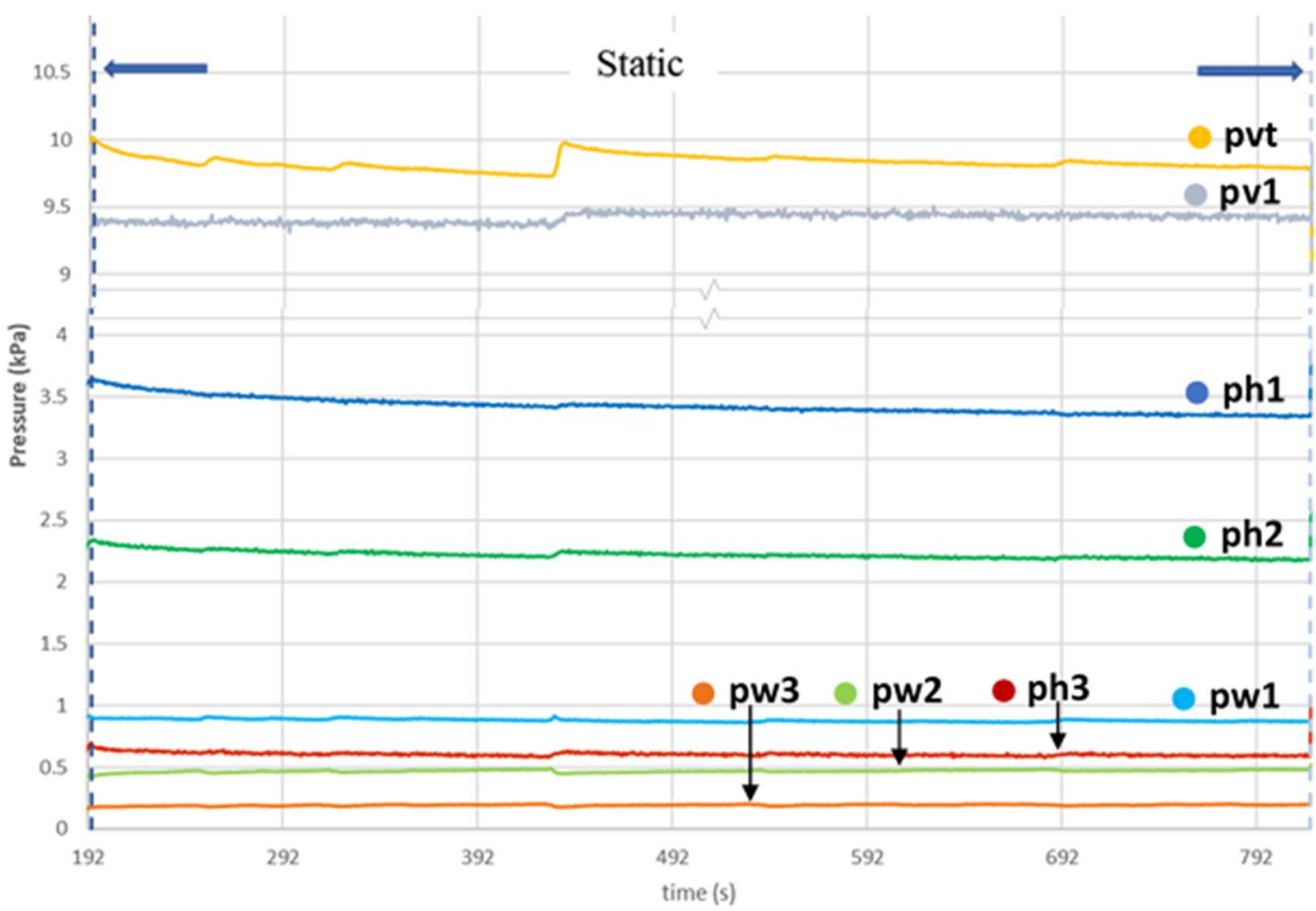

FIGURE 13. Pressures in static condition, flat bottom. 
As shown in Figures 12 and 13, after filling the silo, the frequency of the accommodation peaks decreases over time. This is influenced by the segregation of the material, the variation in the specific weight of the material along the height of the silo and the angle of friction between the product and the silo wall, and the angle of friction of the stored product.

From the figures, the magnitude of the peaks is greater for the $30^{\circ}$ hopper than for the flat bottom, reinforcing the statements regarding the destabilization of the stored product due to the inclination of the hopper.

It is also noted that while normal pressures (ph, i; pnt; pno) oscillated upward, frictional pressures behaved in an opposite manner. The material tends to compact by

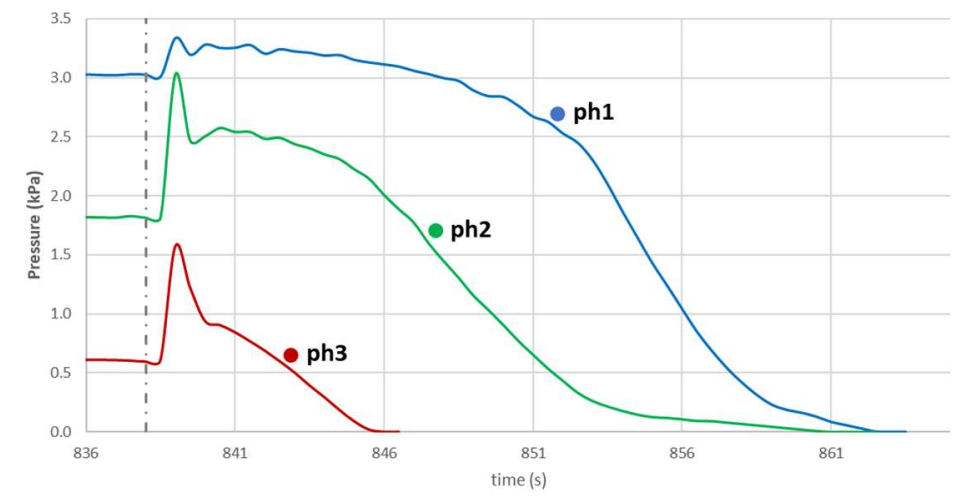

moving vertically (releasing frictional stress), which increases the normal stresses on the cylinder and hopper.

\section{Discharge}

As expected, maximum stresses occur during material discharge (Couto et al., 2013a; Jenike et al., 1973b; Sadowski et al., 2020; Sadowski et al., 2011). It is known that for funnel flow as defined in this paper (ISO, 2012), maximum pressures occur despite the discharge flow being less than the mass flow (Jenike et al., 1973b, 1973a; Wójcik et al., 2012). The pressures in the silo cylinder are shown in Figure 14. Discharge effects occur between $838 \mathrm{~s}$ and $864 \mathrm{~s}$ from the start of the test.

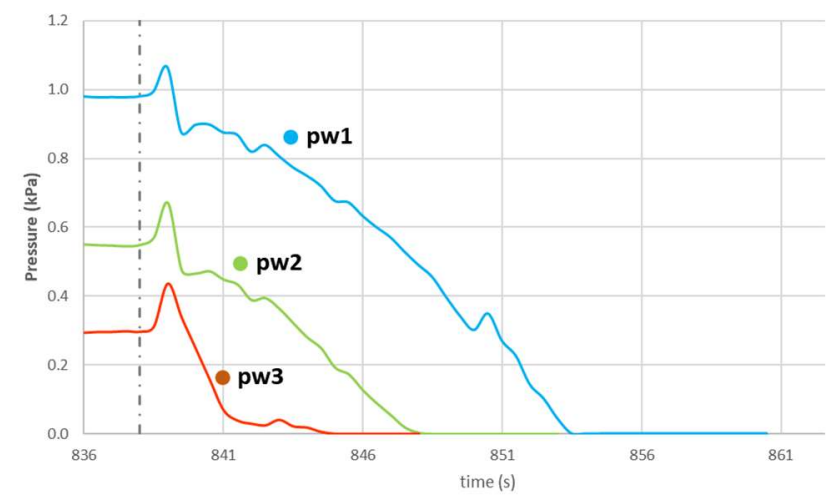

FIGURE 14. Discharge cylinder pressures (normal and frictional), $30^{\circ}$ hopper.

An increase in both friction and normal pressures was observed over the entire cylinder. The flow channel is assumed to form in the middle of the first ring (ph1 and pw1), and as soon as discharge started, the volume of the hopper product was displaced, resulting in a small pressure peak proportional to the displaced volume. The second ring (ph2 and pw2) exhibited the highest pressure peak, indicating the absence of a static zone and a greater volume flow of stored product than through the third ring, inducing greater pressure. The third ring (ph3 and pw3), with less volume of stored product and the absence of a flow channel experienced an overpressure lower than that of the second ring.
The magnitude of the normal overpressure in the silo-hopper transition has been well defined (CEN, 2006; Couto et al. 2013a; Couto et al., 2013b; ISO, 2012; Jenike et al., 1973a), and as expected, the transition area (Figure 15) exhibited the greatest pressure (pnt) under the discharge phase. Mass flow produces higher pressures than incident flow (funnel) (Jenike et al., 1973b; Wójcik et al., 2012), however, the transition area remains as the maximum pressure point in the silo because the state of the stored material changes from static to dynamic.

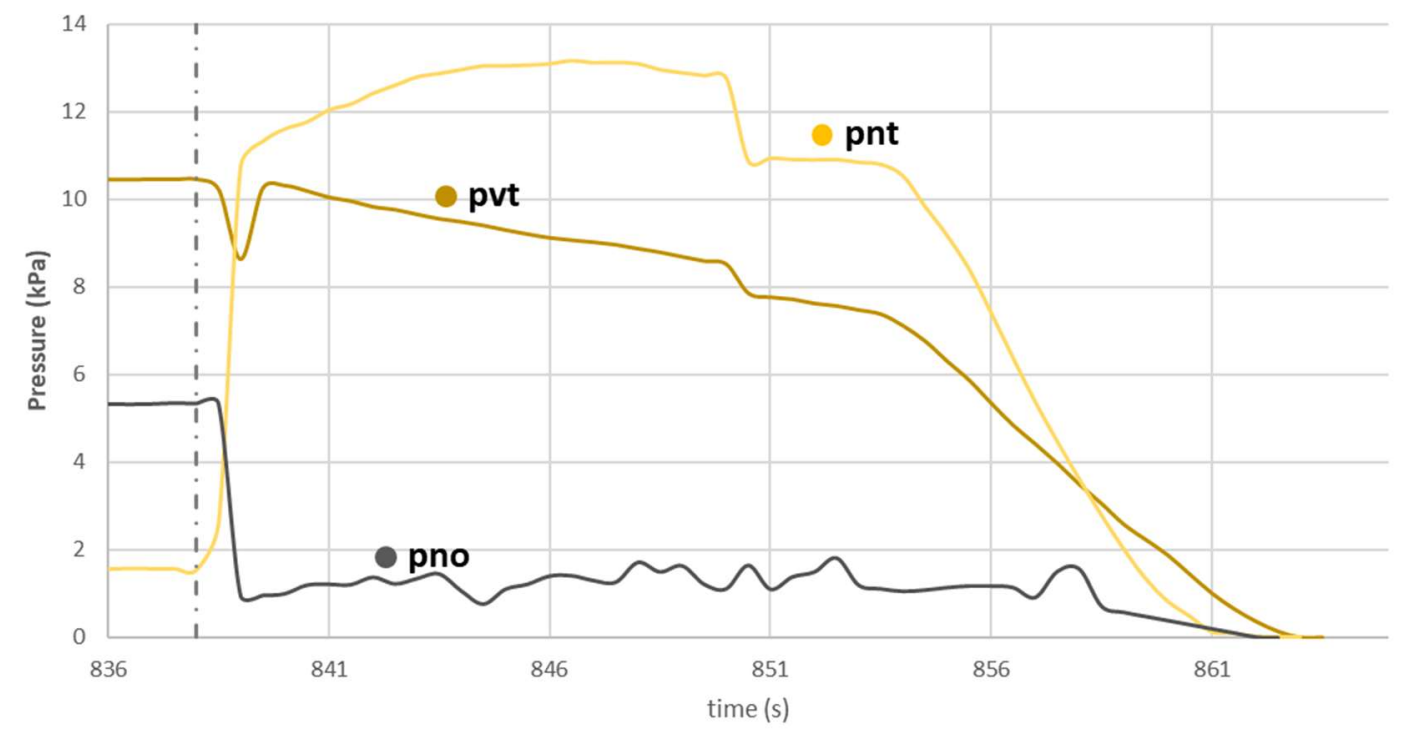

FIGURE 15. Discharge pressures (normal and vertical) in the $30^{\circ}$ hopper. 
The momentary pressure drops observed in pvt occurs because of the relief caused by the beginning of the flow and the movement of the stored product, which is related to the height of the stored product and the inclination of the hopper. This pressure is resumed instantly because from the moment the volume of the stored product is moved

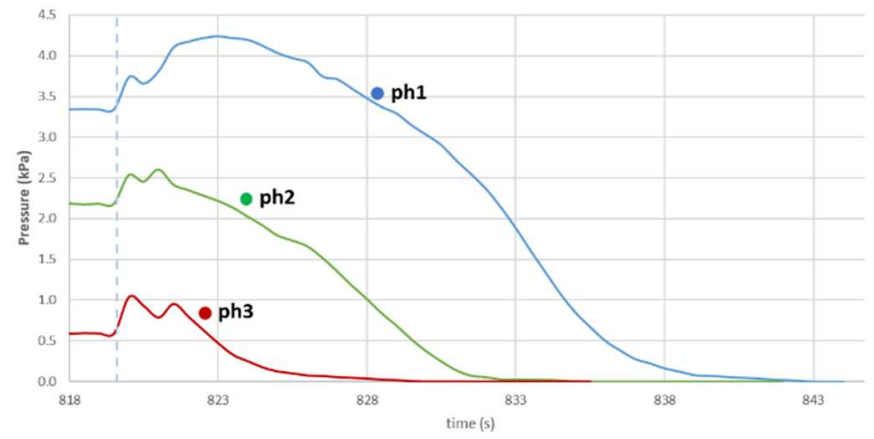

below the transition plane, this space is quickly filled and the pressure is transmitted again to the transition plane.

Discharge effects for the flat bottom occurred between $819 \mathrm{~s}$ and $843 \mathrm{~s}$ from the beginning of the test (Figures 16 and 17).

FIGURE 16. Discharge pressures (normal and frictional) in flat bottom cylinder.

As shown in Figure 16, just after discharge begins, the magnitude of the overpressure is inversely proportional to the height of the silo; in other words, ph1 < ph2<ph3. However, the normal pressure in the first ring (ph1) continues to increase. A possible reason is the collapse of the flow channel formed in the cylinder, causing the pressure to increase over time until the volume stabilizes, after which the pressure decreases.

The frictional temporal pressure in the first ring (pw1) behaves differently from the other rings. A decrease

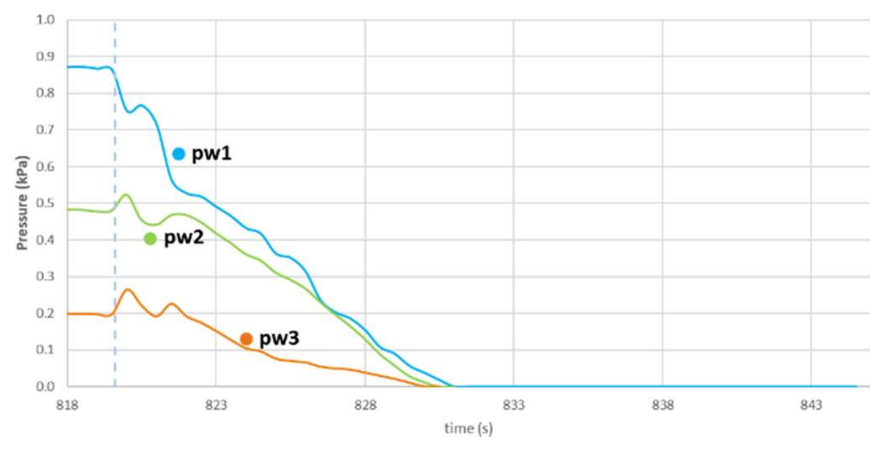

in pressure is observed at the beginning of the flow, reinforcing that the stored product stagnated in that region (a flow channel was present), resulting in less flow, and therefore less vertical force was exerted in the region of the first ring.

The vertical pressure at the bottom of the silo (pv1) and the vertical stress in the stored material at the transition (pvt) exhibit the same behavior because of their proximity within the silo (Figure 17).

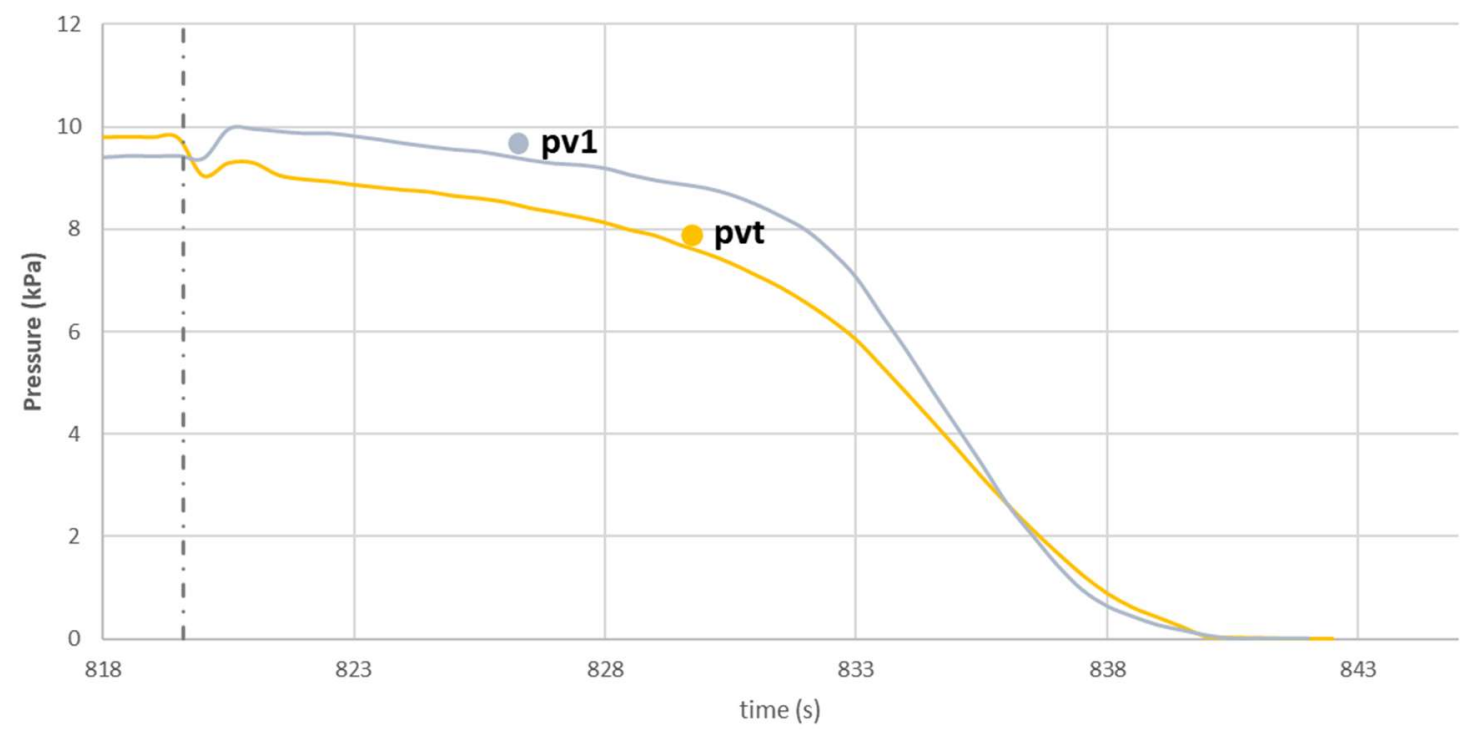

FIGURE 17. Discharge vertical pressures, flat bottom.

The behavior of the pressures in Figure 17 implies the formation of a flow funnel (static zone), because there was no significant increase in pressure in the discharge, which characterizes flow through a funnel (Jenike et al., 1973b).

\section{Maximum pressure}

The maximum normal and frictional experimental pressures for both test configurations ( $\alpha$ : $30^{\circ}$ hopper and flat bottom) were plotted and compared with ISO 11697: 1995 (Figures 18 and 19, respectively). 


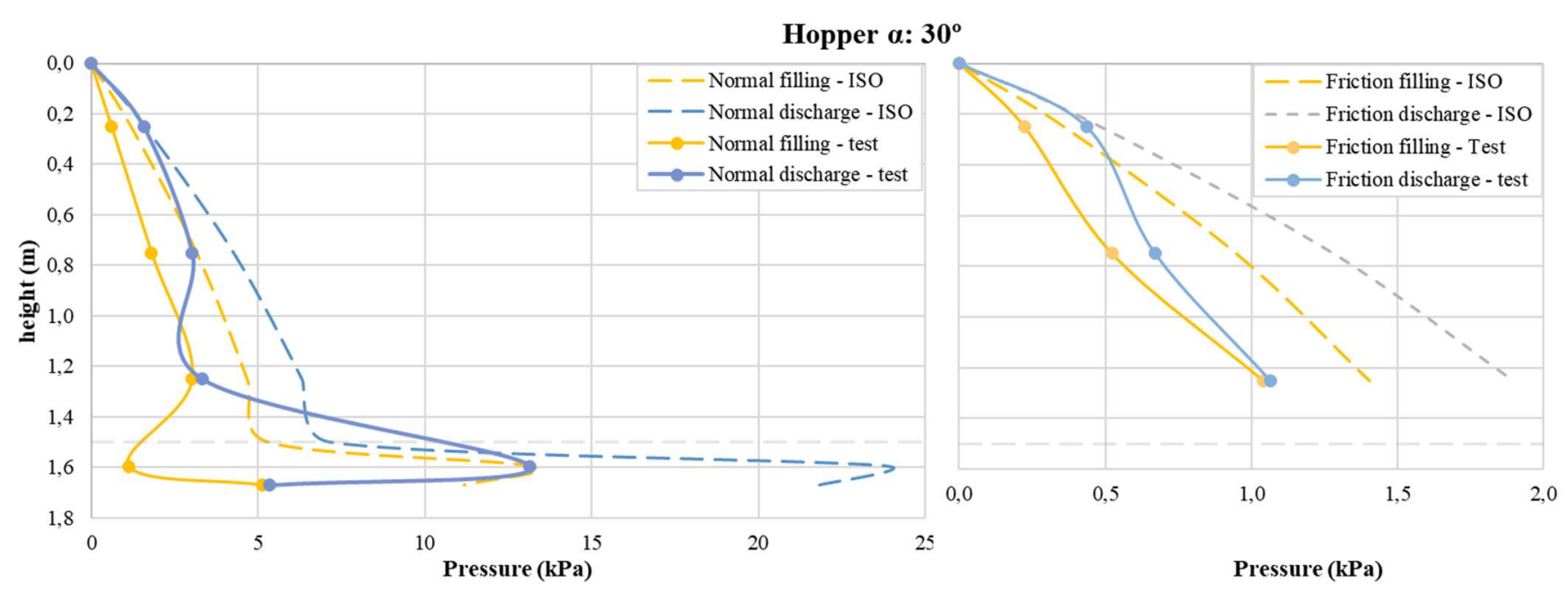

FIGURE 18. Maximum experimental and ISO pressures, $\alpha: 30^{\circ}$ hopper.

The experimental pressures were lower than those published by ISO (ISO, 2012). In order to obtain pressures fitted to the standard, a $35 \%$ " $\mathrm{C}$ " overpressure coefficient is used to account for the slenderness of the cylinder, in addition to the "ps" coefficient representing an increase of $2 * \operatorname{ph} 0$ (where ph0 is the horizontal filling pressure in the parallel section) over an inclined distance of $0.2 *$ diameter of the silo below the transition.

In the results obtained, it was noted that the experimental pressure is $53 \%$ lower than that calculated by the standard in the first ring (ph1) above the transition, and $55 \%$ in the transition region (pnt), demonstrating that the ISO standard aims to provide significant safety factors regarding silo projects.

For a flat bottom silo, the ISO recommends use of the "C" overpressure coefficient related to slenderness, which is $35 \%$. In addition to this coefficient, an empirical safety factor of $35 \%$ must also be applied with respect to the vertical pressure during the filling and discharge phases.

\section{Flat Bottom}
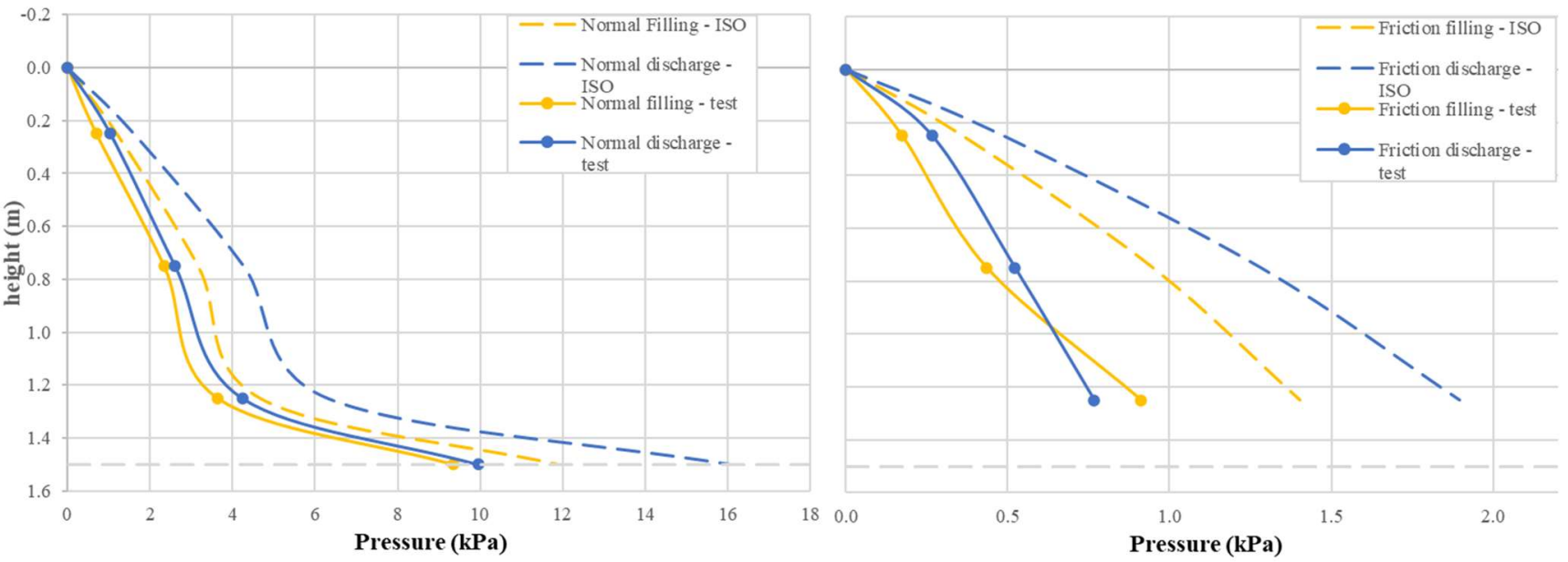

FIGURE 19. Maximum experimental and ISO pressures, flat bottom.

The experimental pressures at the transition region of the silo were lower than those obtained by the standard, which was higher by $22 \%$ in the filling and $38 \%$ in the discharge, demonstrating that the safety factors are sufficient to guarantee safe silo operations based on the results obtained in this study.

A different situation than expected occurred with respect to the frictional pressures, where the maximum pressures occurred during filling and rather than discharge, which was attributed to the height of the effective transition having passed ring 1 . However, the pressure in either phase remained well below the ISO standard.

\section{CONCLUSIONS}

During filling, pressures in the $\alpha: 30^{\circ}$ hopper exhibited accommodation peaks because of the instability caused by the hopper inclination, which differed from the flat bottom results (no oscillations) in this stage. The pressures were not constant in the static condition, exhibiting greater variability in the friction pressures, both in the flat bottom and $30^{\circ}$ hopper configurations.

In general, the normal cylinder pressures were higher for the flat bottom, which was expected, whereas the frictional pressures in the cylinder were higher for the $30^{\circ}$ hopper. 
At discharge, as expected, maximum pressures (normal and frictional) occurred in the cylinder in the $\alpha: 30^{\circ}$ hopper configuration. However, in the flat bottom configuration, the friction pressure was higher during the filling stage than during the discharge phase.

The maximum normal pressures in the $\alpha: 30^{\circ}$ hopper cylinder were approximately half those proposed by ISO 11697. For the flat bottom, the vertical experimental pressures at the transition were $38 \%$ less than those of ISO 11697 , indicating a wide safety margin for silo projects. In both configurations, the frictional pressure on the cylinder was lower than the ISO standard in all phases.

\section{REFERENCES}

ANSI - American Society of Agricultural and Biological Engineers (2019) Loads exerted by Free-Flowing Grain on Bins. ANSI/ASAE.

Brown CJ, Lahlouh EH, Rotter JM (2000) Experiments on a square planform steel silo. Chemical Engineering Science 55(20): 4399-4413. DOI: http://dx.doi.org/10.1016/S0009-2509(99)00574-6

Brown CJ, Nielsen J (1998) Silos: Fundamentals of theory, behaviour and design, London, E \& FN Spon.

Building GED (1989) Standart shear testing technique for particulate solids using the Jenike Shear Cell. Rugby, The Instituition of Chemical Engineers.

Bywalski C, Kamiński M (2019) A case study of the collapse of the over-chamber reinforced concrete ceiling of a meal silo. Engineering Structures 192: 103-112. DOI: http://dx.doi.org/10.1016/j.engstruct.2019.04.100

CEN - European Committee for Standardization (2006) EN 1991-4:2006. Eurocode 1: Actions on Structures. Part 4: Silos and Tanks. CEN.

CONAB, CNA (2020) Acompanhamento da safra brasileira 2019/2020. In: Acompanhamento da Safra Brasileira de Grãos 2019/2020. CONAB. Available: https://www.conab.gov.br/info-agro/safras

Couto A, Ruiz A, Aguado PJ (2012) Design and instrumentation of a mid-size test station for measuring static and dynamic pressures in silos under different conditions - Part I: Description. Computers and Electronics in Agriculture 85: 164-173. DOI:

http://dx.doi.org/10.1016/j.compag.2012.04.009

Couto A, Ruiz A, Aguado PJ (2013a) Experimental study of the pressures exerted by wheat stored in slender cylindrical silos, varying the flow rate of material during discharge. Comparison with Eurocode 1 part 4. Powder Technology 237: 450-467. DOI:

http://dx.doi.org/10.1016/j.powtec.2012.12.030

Couto A, Ruiz A, Herráez L, Moran J, Aguado PJ (2013b)

Measuring pressures in a slender cylindrical silo for storing maize. Filling, static state and discharge with different material flow rates and comparison with Eurocode 1 part 4. Computers and Electronics in Agriculture 96: 40-56. DOI:

http://dx.doi.org/10.1016/j.compag.2013.04.011
DEUTSCHE NORM (2005) DIN 1055-6: Basis of design and actions on structures - Part 6: design 623 loads for buildings and loads in silo bins. Berlin, Verlaz.

Dogangun A, Karaca Z, Durmus A, Sezen H (2009) Cause of damage and failures in silo structures. Journal of Performance of Constructed Facilities 23(2): 65-71. DOI: http://dx.doi.org/10.1061/(ASCE)0887-

3828(2009)23:2(65)

ESALQ, CEPEA, CNA (2021) PIB do agronegócio avança novamente em outubro.

Gandia RM, Gomes FC, Paula WC, Junior EA, Aguado PJ (2021) Static and dynamic pressure measurements of maize grain in silos under different conditions, Biosystems Engineering 209: 180-199. DOI:

https://doi.org/10.1016/j.biosystemseng.2021.07.001.

Gutiérrez G, Colonnello C, Boltenhagen P, Darias JR, Peralta-Fabi R, Brau F \& Clément E (2015) Silo collapse under granular discharge. Physical Review Letters, 114(1), 5-9. DOI:

http://dx.doi.org/10.1103/PhysRevLett.114.018001

Härtl J, Ooi JY, Rotter JM, Wojcik M, Ding S, Enstad GG (2008) The influence of a cone-in-cone insert on flow pattern and wall pressure in a full-scale silo. Chemical Engineering Research and Design 86(4): 370-378. DOI: http://dx.doi.org/10.1016/j.cherd.2007.07.001

IBGE (2020) Levantamento sistemático da produção agrícola - Estatística da produção agrícola. IBGE.

ISO - Internacional Organization for Standardization (2012) ISO 11697:2012. Bases for design of strutures Loads due to bulk materials. ISO.

Janssen HA (1895) Versuche uber getreidedruck in silozellen. Z. Ver. Deutsch Ingineering 39(35): 1045-1049.

Jenike A (1964) Storage and flow of Bulk solids bull. 123. University of Utah.

Jenike AW, Johanson JR, Carson JW (1973a) Bin loadspart 3: mass-flow bins. Journal of Manufacturing Science and Engineering, Transactions of the ASME 95(1): 6-12. DOI: http://dx.doi.org/10.1115/1.3438163

Jenike AW, Johanson JR, Carson JW (1973b) Bin LoadsPart 4: Funnel-Flow Bins. Journal of Engineering for Industry 95: 13-20.

Junior CC, Cheung AB (2007) Silos: pressões, fluxo, recomendações para o projeto e exemplo de cálculo. São Carlos, SET/EESC, USP Ed.

Pieper K, Schütz M (1980) Bericht über das Forschungsvorhaben Norm-Mess-Silo für Schüttguteigenschaften. Hochbaustatik, Technische Universität.

Ramírez A, Nielsen J, Ayuga F (2010a) On the use of plate-type normal pressure cells in silos. Part 1: Calibration and evaluation. Computers and Electronics in Agriculture 71(1): 71-76. DOI:

http://dx.doi.org/10.1016/j.compag.2009.12.004 
Ramírez A, Nielsen J, Ayuga F (2010b) On the use of plate-type normal pressure cells in silos. Part 2: Validation for pressure measurements. Computers and Electronics in Agriculture 71(1): 64-70. DOI:

http://dx.doi.org/10.1016/j.compag.2009.12.005

Ruiz A, Couto A, Aguado PJ (2012) Design and instrumentation of a mid-size test station for measuring static and dynamic pressures in silos under different conditions - Part II: Construction and validation. Computers and Electronics in Agriculture 85: 174-187. DOI: http://dx.doi.org/10.1016/j.compag.2012.04.008

Sadowski AJ, Michael Rotter J, Nielsen J (2020) A theory for pressures in cylindrical silos under concentric mixed flow. Chemical Engineering Science 223: 115748. DOI: http://dx.doi.org/10.1016/j.ces.2020.115748

Sadowski AJ, Rotter JM (2011) Buckling of very slender metal silos under eccentric discharge. Engineering Structures 33(4): 1187-1194. DOI:

http://dx.doi.org/10.1016/j.engstruct.2010.12.040

Sun W, Zhu J, Zhang X, Wang C, Wang L, Feng J (2020) Multi-scale experimental study on filling and discharge of squat silos with aboveground conveying channels. Journal of Stored Products Research 88: 101679. DOI:

http://dx.doi.org/10.1016/j.jspr.2020.101679
Teng BJ (1994) Plastic Collapse at lap joints in pressurized cylinders under axial load. Journal of Structural Engineering 120(1): 23-45.

Teng JG, Rotter JM (1989) Plastic collapse of restrained steel silo hoppers. Journal of Constructional Steel Research 14(2): 139-158. DOI: http://dx.doi.org/10.1016/0143-974X(89)90020-5

Teng J, Rotter JM (1991) Collapse Behavior and Strength of Steel Silo Transition Junctions. Part I: Collapse Mechanics. Journal of Structural Engineering 117(12): 3587-3604. DOI: http://dx.doi.org/10.1061/(asce)07339445(1991)117:12(3587)

Walker D (1967) An approximate theory for pressures and arching in hoppers. Chemical Engineering Science 22(3): 486. DOI: http://dx.doi.org/10.1016/0009-2509(67)80145-3

Walters JK(1973a) A theoretical analysis of stresses in axially-symmetric hoppers and bunkers. Chemical Engineering Science 28(3): 779-789. DOI: http://dx.doi.org/10.1016/0009-2509(77)80012-2

Walters JK (1973b) A theoretical analysis of stresses in silos with vertical walls. ChemicalEngineering Science 28: 13-21.

Wójcik M, Tejchman J, Enstad GG (2012) Confined granular flow in silos with inserts - Full-scale experiments. Powder Technology 222: 15-36. DOI:

http://dx.doi.org/10.1016/j.powtec.2012.01.031 